\title{
Structure and Magnetic Properties of Amorphous Fe-Zr-Nb-Cu-B-(Y) Ribons
}

\begin{abstract}
JOANNA GONDRO*
${ }^{1}$ Institute of Physics, Faculty of Production Engineering and Materials Technology, Czestochowa University of Technology, 19 Armii Krajowej Str., 42-200 Czêstochowa, Poland

In this paper the results of the structural and magnetic properties for amorphous alloys ribbons $\mathrm{Fe}_{8} \mathrm{Zr}_{-} \mathrm{Nb}_{2} \mathrm{Cu} \mathrm{B}_{5}$ and $\mathrm{Fe}_{8} \mathrm{Zr}_{4} \mathrm{Y}_{3} \mathrm{Nb}_{1} \mathrm{Cu} \mathrm{B}_{5}$ were presented. From X-ray diffraction and Mössbauer investigations we have stated thatamorphous ribbons were fully amorphous. The investigated alloys, exhibit poor softmagnetic properties at room temperature. However, at low temperatures they show relatively large magnetic susceptibility and good its time stability.
\end{abstract}

Keywords: ribbons alloys, amorphous structure, Mössbauer spectroscopy, X-ray diffraction

The soft magnetic amorphous alloys are characterized by a low value of the coercive field, small losses for remagnetization and a large initial magnetic permeability [1-8]. One of the advantages of soft magnetic alloys is the possibility of their re-magnetization

in relatively low magnetic fields, which is important for example in the production of magnetic refrigerators. In recent years, a number of studies have been developed regarding materials that could be used as an alternative technology for traditional refrigerators. The phenomenon which is used in magnetic cooling is the magnetocaloric effect observed as a change in the temperature of appropriate magnetic materials during their remagnetization $[9,10]$. The final magnetic properties of amorphous alloys depend on the chemical composition but also on the proper thermal treatment [11-21].

The wide technological progress in the production of magnetic materials has led to the development of magnetic circuits and sensors. Materials with softmagnetic properties find great use in transformer cores, chokes or sensitive residual current devices. The application possibilities of soft magnetic materials forced the search for more and more useful properties from the point of view of their applicability in power engineering or electronics. For example, materials used in power industry should have the lowest possible loss, allowing for high efficiency in energy conversion.

As it is known, amorphous alloys are characterized by a lack of ordering of the long range of atoms, this fact can be confirmed with the use of Mössbauer spectrometry [22].

Obtained Mössbauer spectra for these alloys consist of wide lines, which is associated with the presence of a variable environment of Mossbauer atoms as a result of chemical and topological disorder. However, the analysis of these spectra may give information about the heterogeneity of the tested alloy, and thus on the occurrence of various concentrations of atoms. Obtained spectra are often asymmetrical, which is mainly caused by the anisotropy of the magnetic hyperfine field and the dependence of the isomeric shift on the intensity of the hyperfine magnetic field [23].

Studies on the structure of amorphous alloys can also be carried out using neutron scattering [24]. Amorphous alloys obtained in the form of thin strips with a thickness of about 20-30 $\mu \mathrm{m}$, are produced as a result of rapid solidification of the liquid alloy on a spinning copper wheel.
The process of producing amorphous tapes usually takes place at a cooling rate of more than $10^{4} \mathrm{~K} / \mathrm{s}$. An important parameter of the soft magnetic materials talking about their possible electrotechnical application are the $P$ loses, defined as the total active power absorbed by the magnetism in the variable magnetic field, to the unit of its mass.

Losses $P_{\text {his }}$ from hysteresis, losses from eddy currents $P_{c}$ and additional losses $P$ make up the total losses for remagnetization in magnetic materials $[25,26]$ :

$$
P_{t}=P_{\text {his }}+P_{c l}+P_{\text {texc }}
$$

The value of the energy lost for the re-magnetization depends mainly on the density, thickness, resistivity of the material, as well as the frequency $(\mathrm{f})$ and the amplitude of the magnetic induction (B). Losses $P$ from hysteresis are associated with chemical composition, structure and stresses in the material. Their value determines the static surface area of the hysteresis loop and increases with increasing frequency as a result of adding losses from each remagnetization. The vortex losses depend on the resistivity, while the additional losses result from the domain structure of the magnetic material. These losses are directly proportional to the energy absorbed by the movement of domain walls during magnetization. The value of energy is the higher the more obstacles (defects) that block the movement of domain walls.

Dependencies of the type $B=f(H)$, where $B$ is an induction corresponding to the field strength $\mathrm{H}$ in the material under study, is one of the basic characteristics of magnetic materials. Static characteristics determined in the fixed field and those defined in the alternating field (dynamic), can be distinguished. From the user's point of view, more interesting are the dynamic characteristics, which are measured on closed toroidal or frame - tpe or open samples of various shapes described in national and European standards. Due to the shape of the tested sample, it stands out, among others systems for testing closed toroidal samples. The sample should be completely closed, the material should be homogeneous with a small width compared to the internal diameter, ensuring an even distribution of the field in the entire sample cross-section. The disadvantages of annular samples include labor consumption during their winding and possible temperature losses for high intensity magnetic fields. However, the big advantage is the fact that almost the entire magnetic flux is closed in the sample. 
Analysis of losses in the case of amorphous alloys due to the presence of a complex magnetic structure, allows to determine the relationship between the microstructure of the tested alloy sample and losses to remagnetize.

The paper presents the results of research on the structure and magnetic properties of amorphous alloys $\mathrm{Fe}_{86} \mathrm{Zr}_{7} \mathrm{Nb}_{1} \mathrm{Cu}_{1} \mathrm{~B}_{5}$ and $\mathrm{Fe}_{86} \mathrm{Zr}_{4} \mathrm{Y}_{3} \mathrm{Nb}_{1} \mathrm{Cu}_{1} \mathrm{~B}_{5}$ in the as quenched state.

\section{Experimental part}

Ingots of the tested alloys obtained from high purity elements (99.99\%) were melted in an electric arc, and then using the technique of rapid solidification of molten material on a rotating cylinder, samples were obtained in the form of $20 \mathrm{im}$ thick and $3 \mathrm{~mm}$ wide tapes. The microstructure and magnetic properties of the sample were investigated, both in the as-quenched state. Mössbauer spectrometer, equipped with a 57Co (Rh) source with an activity of $50 \mathrm{mCi}$. The transmission Mössbauer spectra were analysed using 'NORMOS' [27] software. X-ray examinations were carried out using an $X$ ray diffractogram (Brucker Advanced D8). Measurements were made in the range of $2 \theta$ angle from $30^{\circ}$ to $130^{\circ}$ with a measuring step of $0.02^{\circ}$ and exposure time of $7 \mathrm{~s}$. Measurements were made in Bragg-Brentano geometry, semiconductor counter and CuK $\theta \alpha$ lamp.

The losses for the re-magnetization were measured using ferrometer in a magnetizing field with a frequency of $50 \mathrm{~Hz}-1000 \mathrm{~Hz}$. For the tested alloy samples in the form of tapes, the measurement was made for a toriodic bifilar winding. The even winding allowed to minimize the effects of distraction and to limit the value of errors that may result from sample heterogeneity. The magnetic parameters of the tested material were calculated on the basis of measured values of signals: unloaded secondary voltage and primary current supplied with a test signal.

\section{Results and discussions}

The amorphous nature of the investigated alloys in solidified state was confirmed by X-ray diffraction pattern analysis related to the results obtained with Mossbauer spectra.

$X$-ray diffraction images for the investigated samples: $\mathrm{Fe}_{86} \mathrm{Zr}_{1} \mathrm{Nb}_{1} \mathrm{Cu}_{1} \mathrm{~B}_{5}(\mathrm{a}), \mathrm{Fe}_{86} \mathrm{Zr}_{4} \mathrm{Y}_{3} \mathrm{Nb}_{1} \mathrm{Cu}_{1} \mathrm{~B}_{5}$ (b) in the asquenched state are presented in figure 1 .

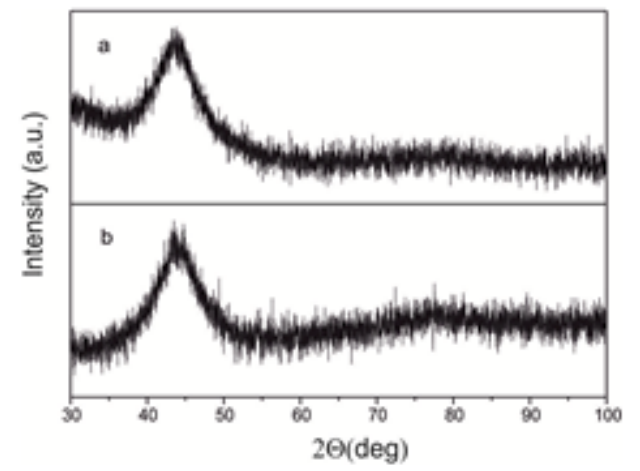

Fig. $1 \mathrm{X}$-ray diffraction patterns for the investigated alloys:

$$
\mathrm{Fe}_{86} \mathrm{Zr}_{7} \mathrm{Nb}_{1} \mathrm{Cu}_{1} \mathrm{~B}_{5}(\mathrm{a}), \mathrm{Fe}_{86} \mathrm{Zr}_{4} \mathrm{Y}_{3} \mathrm{Nb}_{1} \mathrm{Cu}_{1} \mathrm{~B}_{5} \text { (b). }
$$

These images are characteristic of amorphous alloys and there are no narrow maxima typical of the crystalline phase, while the wide maxima at the angle $2 \theta$ of about $45^{\circ}$ are visible.

Observed Mössbauer spectra have the form characteristic of magnetically soft ferromagnetic materials [28-30]. The low and high field components visible in the hyperfine index distributions give information about the

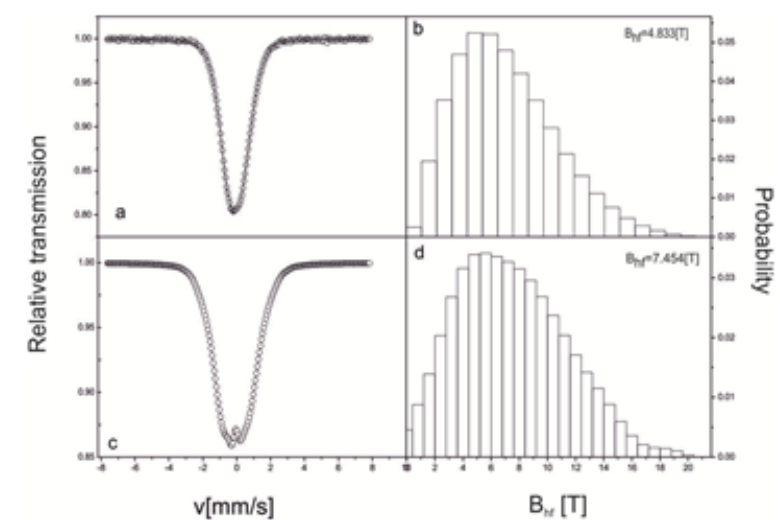

Fig. 2. Transmission Mossbauer spectra $(a, c)$ and corresponding hyperfine field distributions ( $b, d)$ for the amorphous alloys: $\mathrm{Fe}_{86} \mathrm{Zr}_{7} \mathrm{Nb}_{1} \mathrm{Cu}_{1} \mathrm{~B}_{5}(\mathrm{a}, \mathrm{b})$ and $\mathrm{Fe}_{86} \mathrm{Zr}_{4} \mathrm{Y}_{3} \mathrm{Nb}_{1} \mathrm{Cu}_{1} \mathrm{~B}_{5}(\mathrm{c}, \mathrm{d})$ in the asquenched state

occurrence of areas with different iron concentrations in the alloy. On their basis, it can also be stated that the examined alloys are relatively homogeneous. In the case of an alloy containing the yttrium, the contribution of the paramagnetic component is visible, which results from the fact that the probability is not equal to zero for $B_{h f}=0$.

Figure 3 and 4 show the dependence of the maximum permeability as a function of magnetic field strength for the tested alloys.

On the curves (fig. 3,4 ) the maximum is visible, which corresponds to the maximum permeability ìmax. For $\mathrm{Fe}_{8} \mathrm{Zr}_{7} \mathrm{Nb} \mathrm{Cu}_{1} \mathrm{~B}_{5}$ alloy. The maximum permeability is about 7,000 , and for the alloy $\mathrm{Fe}_{86} \mathrm{Zr}_{4} \mathrm{Y}_{3} \mathrm{Nb}_{1} \mathrm{Cu}_{1} \mathrm{~B}_{5}-8000$ [31]. In both cases it is visible that the maximum susceptibility decreases with the increase in the frequency of the magnetizing field. A higher value of imax indicates a greater relaxation of the structure in the alloy containing the yttrium.

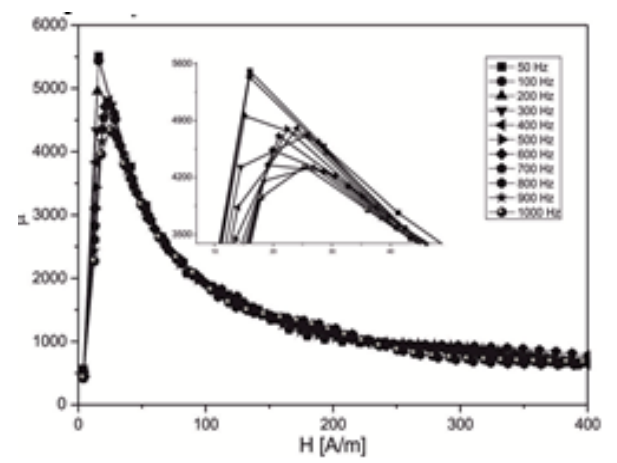

Fig. 3. Magnetic permeability as a function of the amplitude of the magnetic field for $\mathrm{Fe}_{86} \mathrm{Zr}_{7} \mathrm{Nb}_{1} \mathrm{Cu}_{1} \mathrm{~B}_{5}$ alloy.

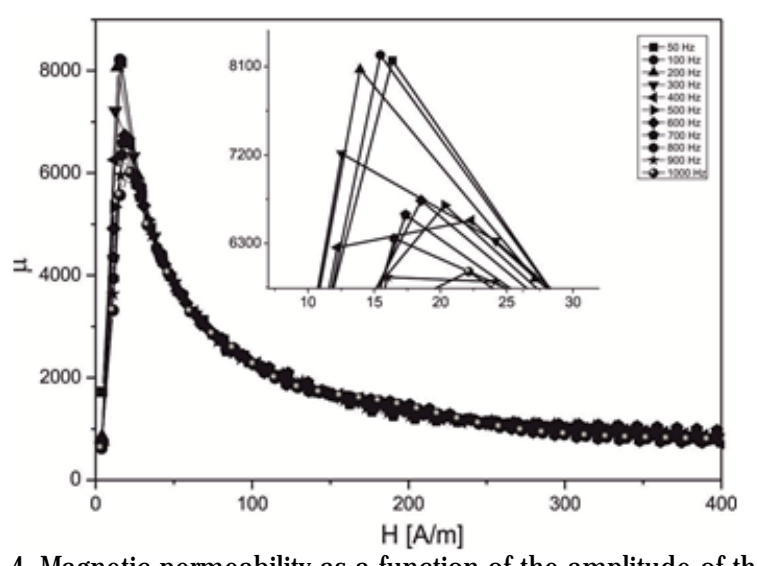

Fig. 4. Magnetic permeability as a function of the amplitude of the magnetic field for $\mathrm{Fe}_{86} \mathrm{Zr}_{4} \mathrm{Y}_{3} \mathrm{Nb}_{1} \mathrm{Cu}_{1} \mathrm{~B}_{5}$ alloy 


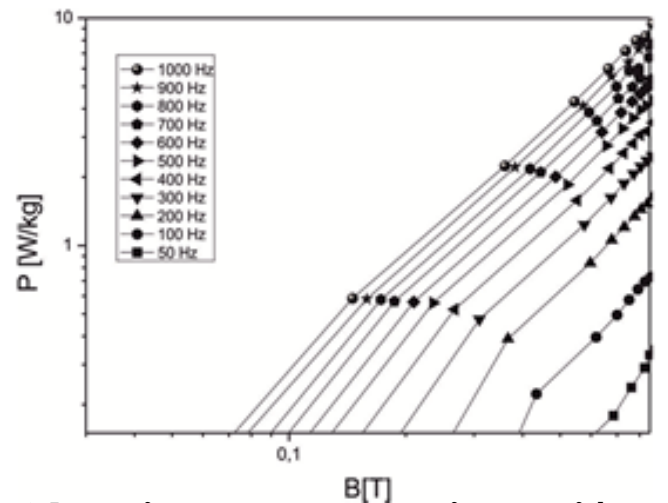

Fig. 5. Losses for remagnetization as a function of the maximum induction for the alloy $\mathrm{Fe}_{86} \mathrm{Zr}_{7} \mathrm{Nb}_{1} \mathrm{Cu}_{1} \mathrm{~B}_{5}$

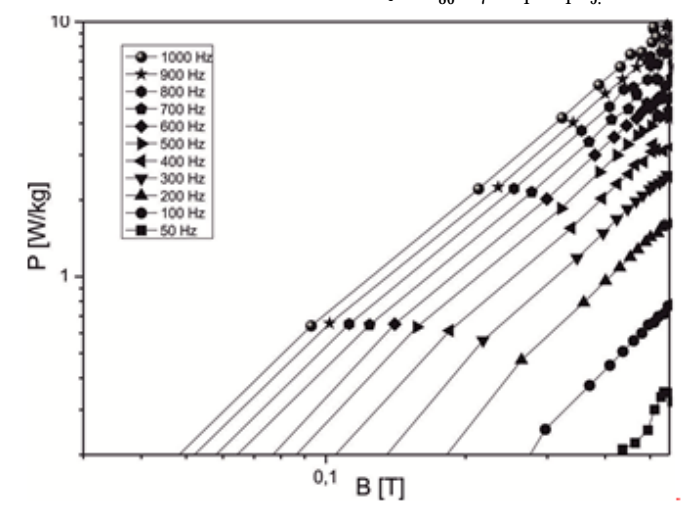

Fig. 6 Losses for remagnetization as a function of the maximum induction for the alloy $\mathrm{Fe}_{86} \mathrm{Zr}_{4} \mathrm{Y}_{3} \mathrm{Nb}_{1} \mathrm{Cu}_{1} \mathrm{~B}_{5}$.

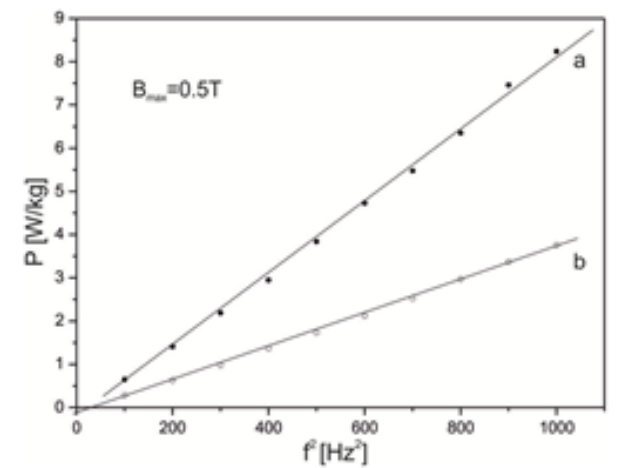

Fig. 7 Lusses UI IIIaynleu<auuil as a IuIlcuvil vi uie syuare of the frequency of the magnetizing field for massive amorphous alloys:

$\mathrm{Fe}_{86} \mathrm{Zr}_{7} \mathrm{Nb}_{1} \mathrm{Cu}_{1} \mathrm{~B}_{5}(\mathrm{a}), \mathrm{Fe}_{86} \mathrm{Zr}_{4} \mathrm{Y}_{3} \mathrm{Nb}_{1} \mathrm{Cu}_{1} \mathrm{~B}_{5}(\mathrm{~b})$ with $\mathrm{B}_{\max }=0.5 \mathrm{~T}$

In the magnetic fields above about $0.4 \mathrm{H}_{c}\left(\mathrm{H}_{c}\right.$ - coercive field), irreversible magnetization processes occur during the magnetization of the alloy. As a result, a magnetic hysteresis loop is observed, which is a measure of losses for remagnetization. Figure 5 and 6 show the losses for remagnetization for received materials.

On the basis of the core losses changes (fig. 4, 5) one can state that the obained materials are magnetically soft. The total losses at low frequencies are comparable with these observed in classical silicon-iron alloys.

Figure 7 shows the increase in losses along with the square of the frequency of the magnetizing field. This dependence is linear, which indicates that in the materials studied there are mainly losses from magnetic hysteresis and eddy currents. The share of additional losses is negligible.

\section{Conclusions}

Investigated alloys obtained by the injection casting method are fully amorphous. For the better use of soft magnetic materials in various devices and electrical elements, there is a need to precisely define and characterize appropriate properties that will eventually allow to design cheaper or more energy-efficientmaterials. Most of this point of view the desired size of the core loss, and its relationship with the domain structure of soft ferromagnetic. Reduction of core losses can improve their magnetic properties and thus make better use of their application. Taking into account the values of the core losses one can state that the total losses at low frequencies are comparable with core losses observed in classical FeSi alloys.

\section{References}

1.SUZUKI K., MAKINO A., INOUE A., MASUMOTO T., J. Appl. Phys. 70, 1991, 6232

2.SLAWSKA-WANIEWSKA A., NOWICKI P. , LACHOWICZ H. K., GORRIA P., BARANDIARA J. M.,HERNANDO A., Phys Rev. B 50, 1994, 6465

3.GRUSZKA K., NABIAfEK M., B£OCH K., OLSZEW SKI J ., Nukleonika 60, 2015, pp. 23-2

4.RZ¥CKI K., BfOCH K., WALTERS S., Acta. Phys. Pol. A, 131, 2017, pp. $720-722$

5.INOUE A., KOSHIBA H., ITOI T., MAKINO A., Appl. Phys. Lett. 73, 1998, pp. 744-746

6.NABIALEK M., Arch. Metall. Mater.61, 2016, pp. 445-450

7.PIETRUSIEWICZ P., K. BLOCH., NABIAAEK M., WALTERS S., Acta Phys. Pol. A, 127 no 2, 2015, pp. 397-399

8.SZOTA M., Arch. Metall. Mater. 60 (4), 2015, p. 3095-3100

9.BRÜCK E., TEGUS O., THANH D.T.C., BUSCHOW K.H.J., J. Magn. Magn. Mater. 310, 2007, e2793-e2799

10.SKORVANEK I., KOVAC J., MARCIN J., SVEC P., JANICKOVIC D., Mater. Sci. Eng. A 449-451, 2007, p. 460-463.

11.GONDRO J ., J. Magn. Magn. Mater., 432, 2017, p. 501-506

12.NABIAfEK M., J. Alloys Comp., 642, 2015, pp. 98-103

13.BLOCH K., J. Magn. Magn. Mater., 390, 2015, p. 118-122

14.PERJU, M.C., NEJ NERU, C., GALUSCA, D.G., STEFANICA, R.G., Modtech 2010: New Face of TMCR, Proceedings, 2010, p. 455.

15.LARGEANU, A.E., NEJ NERU, C., PERJU, M.C., GALUSCA, D.G., Metalurgia International, vol. XVI, no.5, 2011, pg. 43-46.

16.MINCIUNA, M.G., VIZUREANU, P., ACHITEI, D.C.,GHIBAN, B., SANDU, A.V., MARECI, D., BALAN, A., Rev.Chim.(Bucharest), 65, no. 10,2014, p 1138

17.ACHITEI, D.C., VIZUREANU, P., DANA, D., CIMPOESU, N., Metalurgia International, 18, SI2, 2013, p. 104.

18.CHIRILA, E., SUSAN, M., GAVRILA, B.L., SANDU, A.V., Rev.Chim.(Bucharest), 64, no. 5, 2013, p. 482.

19.PUSKAS, A., CORBU, O., KOLLO, S.A., MODERN TECHNOLOGIES FOR THE 3RD MILLENNIUM, 2017, p. 239.

20.BINDEA, M., CHEZAN, C.M., PUSKAS, A., J ournal of Applied Engineering Sciences, 5, no. 1, 2015, p. 7.

21.GRUSZKA K., Materiali in tehnologije/Materials and technology 50, 2016, pp.707-718

22.BHATNAGAR A. K., PRASAD B. B., JAGANNATHAN R., Phys. Rev. B 29, 1984, p. 4896-4903

23.KOHLBRECHER J., WIEDENMANN A., WOLLENBERGER H., Phys. B 104, 1997, p. 1-4

24.OLSZEW SKI I ., Politechnika Czestochowska, seria Monografie 119, 2006

25.KRONMULLER H., REININGER T., J. Magn. Magn. Mater. 112, 1992, p. 1-5

26.PICCIN R., TIBERTO P., CHIRIAC H., BARICCO M., J. Magn. Magn. Mater. 320, 2008, p. 806-809

27.BRAND R.A., Nucl Instrum Meth B 28, 1987, p. 398-416

28.KAUL S.N., SIRUGURI V., CHANDRA G., Phys. Rev. B 45, 1992, p. $12343-12356$.

29.MAKAROV V.A., BELENKII A.YA., KOZLOVA O.S., Phys Stat. Sol. (A) 139, 1993, p. 173-179.

30.CHAPPERT J., COEY J.M.D., LIENARD A., J. Phys. F: Met. Phys.,11, 1981, p. 2727-2744

31.BOZORTH R. M., Ferromagnetism, IEEE Press, New York, 1993

$\overline{\text { Manuscript received:19.07.2018 }}$ 